\title{
Preparationof Indian Lion(Leo panthera) Skeleton for Exhibition at Chittagong Zoo
}

\section{S. I. Khan ${ }^{1}$ M.M.Chowdhoury², M. M. Rahman ${ }^{3}$, M. S. H. Suvo $^{4}$, M. R. Begum ${ }^{5}$}

\begin{abstract}
${ }^{1}$ Md. Shafiqul Islam Khan, Assistant professor of Food microbiology, Patuakhali Science and Technology University, Bangladesh.

${ }^{2}$ Monjur MorshedChowdhury,Veterinary Officer, Chittagong Zoo, Chittagong, Bangladesh.

${ }^{3}$ Md. MostafizurRahman, Technical veterinary Officer, ACI Limited, Bangladesh.

${ }^{4} \mathrm{Md}$ ShahadatHossainSuvo, Veterinary Surgeon, Chittagong Zoo, Chittagong, Bangladesh.

${ }^{5}$ Musammet Rasheda Begum, Assistant professor of Biostatistics, Chittagong Veterinary and Animal Sciences University, Chittagong, Bangladesh
\end{abstract}

With 2 figures

\section{Abstract}

Skeletons are the archetypal image of anatomy and necessary for research ranging from phylogenic investigations to age and growth to functional morphology. A quick and efficient technique wasappliedto prepare completely cleared and natural white shining skeleton of Indian lion was done in Chittagong zoo for exhibition. After death of the lion of this zoo, the carcasswasbluntlydefleshed,segmented of the body stored in $10 \%$ solution of soda water for 1 month and after complete cleaning, the bony segments dipped into $10-20 \%$ solution of bleaching water for 2 days and then washed in tap water and after complete sundry, the bony segments were articulated for raising skeleton. This preparing skeleton by quick method was very gleaming natural white and this skeleton now kept in a temporary museum of zoo which becomes interesting tools for visitors especially for children.

Keywords: Indian lion, modifiesmethod, Skeleton, Exhibition.

\section{Introduction}

Skeleton is the framework of hard structure which supports and protects the soft tissues of animals and birds (Getty, 1975). These skeletons arenecessary for research ranging from phylogenic investigations to age and growth analyses to functional morphology (Bemis et al., 
2004; Olson, 1973; Burke \&Feduccia, 1997), and are preserved in museums, institutes, and organizations for the protection of nature and schools use skeleton in research and teaching (Bemis et al., 2004). Large series of skeletons provide a sound basis for assessing geographic size variation within a species. Skeletons are essential for the identification of fossils, bones from archaeological sites and food items taken by predatory animals. Although world skeletal inventories have greatly aided researchers, they also reveal serious deficiencies in museum holdings (Olson, 2003). Raghavan (1964) describes the traditional method of preparation of skeleton which may be required about 1 to 2 months. Selby (1987) describes a simple three-day technique for preparing skeleton of adult mice. Preparation of skeleton of wild animal and its exhibition may be interesting tools for zoo education. In this experiment, our aim was to prepare a lion skeleton with quick method for exhibition.

\section{Materialand Methods}

A dead Indian lion was used in this experiment. Preparing animal skeletons does require some care where health and safety are concerned. So we used rubber gloves when preparingthecarcass and care was tak- en to avoid stick injuries following the concept of Baker et al. (2003).

\section{Skinning andmechanical removal of meat}

The dead animal was carried to the dissection room and put on the floor. The skin and muscles along with other adipose tissue and visceral organs were removed with the help of BP handle and blades, forceps, up to maximum extent as possible, so that the bones were visible.

\section{Decomposing the remaining meat, tendon and ligaments}

The bony bodies were boiled in $10 \%$ solution of soda water for 30 days so that soda water solution completely digeststhe muscles, tendons and ligaments. Body segments were taken out and again the left over flesh and tissue on the bones were scratched by BP handle and blade as maximum as possible.

\section{Washing of the bones}

The ribs were tightly knotted serially in situ condition of skeleton and gently pulled away the backbone. A thick wire was driventhrough vertebral column as much as possible to keep the natural order of vertebrae.Then each leg, skull, vertebral column, rib and sternum waswashed separately with normal water. Later bones were then 
dipped into $10-20 \%$ bleaching water solution for 2days. Finally drying ofbones was done after washing with water.

\section{Assembling the bones into skele- ton}

Then the bones were articulated and raised into the skeleton (Fig1a,1b). The ribs were attached to the preformed backbone by small, non-corrosive wires and necessary drilling .Each leg was framed separately and attached with in position. The skull was articulated with thevertebral column to complete the skeleton. A hard pavement was prepared on which skeleton was raised in life-like pose with the help of rods and wires.

\section{Conclusion}

A beautiful lion skeleton is raised and kept in temporary museum for exhibition purpose which becomes very attractive to the visitors especially for children in Chittagong zoo. Preparation of others wild skeleton may be the important tools to increase the opportunity of zoo education.

\section{References}

Bemis WE, Hilton EJ, Brown B, Arrindell R, Richmond AM, Little CD, Grande L, Forey PL, Nelson
GL. (2004): Methods for preparing dry, partially articulated skeletons of osteichthyans, with notes on making ridewood dissections of the cranial skeleton. Copeia. 3: 603-609.

Burke AC,Feduccia A. (1997): Developmental patterns and the identification of homologies in the avian hand. Science.278: 666-668.

Baker P, Davis S, Payne S, RevillM. (2003): On preparing animal skeletons - a simple and effective method.International Council for Archaeozoology, Newsletter vol. 4 (1): $4 \& 15$.

Getty R. (1975): General osteology. The Anatomy of the Domestic Animals, Vol-1, $5^{\text {th }}$ Ed., W. B. Saunders Company,Philadelphia.P-19.

Olson SL. (1973): Evolution of the rails of the South Atlantic Islands.Smithsonian Contributions to Zoology. 152.

Olson SL. (2003): Development and uses of avian skeleton collections. Bulletin of BritishOrnithologist's Club . (123A): 26-34.

Raghavan D. (1964): Anatomy of Ox. Indian Council of Agriculture Research, New Delhi.

Selby PB. (1987): A rapid method for preparing high quality aliza- 
rinstained skeletons of adult mice. Stain Technology.62(3):143-6.

\section{Acknowledgements}

\section{Corresponding author:}

Md. Shafiqul Islam Khan

Assistant professor of Food microbiology

PatuakhaliScience and Technology University, Bangladesh.

Phone number: +8801712115973

Email:msikhan312@yahoo.com / msikhan312@gmail.com
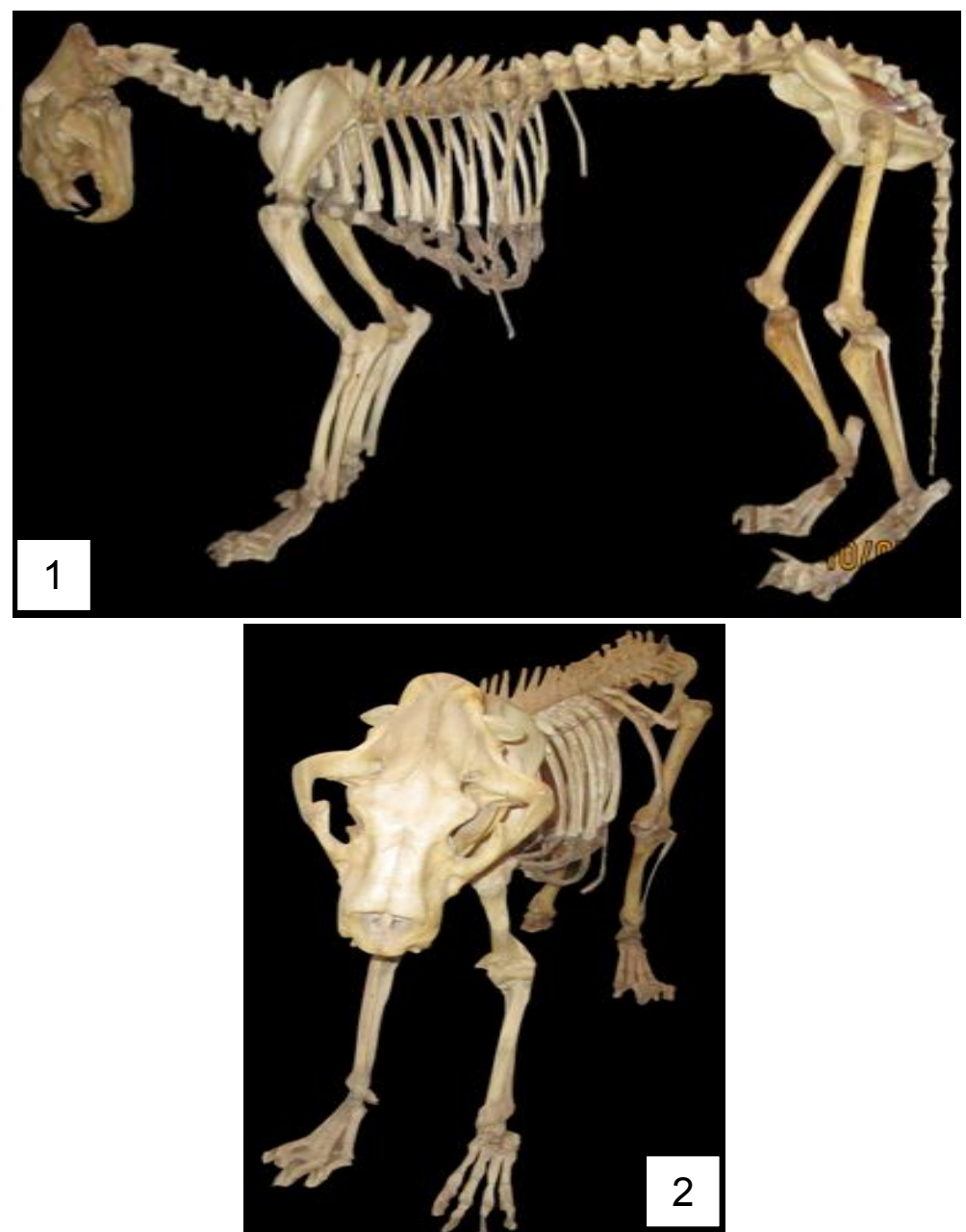

Fig (1): Lateral view of the lion skeleton

Fig (2): Craniolateral view of the lion skeleton
Chittagong zoo to successfully prepare and setting of the skeleton. 